\title{
Association of tumor necrosis factor-alpha G-308 a polymorphism with inflammatory markers and lipid profile in coronary heart disease
}

\author{
Sangita Mahadev Patil', (1) Mangesh P Bankar², (1) Ramchandra K Padalkar² \\ 'Department of Biochemistry, Dr. Vithalrao Vikhe Patil Foundations Medical College Ahmednagar, Maharashtra, India \\ ${ }^{2}$ Department of Biochemistry, B.J. Medical College Pune, Maharashtra, India
}

\begin{abstract}
Objectives: Tumor necrosis factor-alpha (TNF-a) is a primary proinflammatory cytokine. Single nucleotide polymorphisms present in the promoter region of cytokines have been implicated in the cardiovascular disease pathogenesis. Thus, this study aims to understand the role of permissive promoter variants in TNF-a G-308 A and its correlation with inflammatory markers and lipid profile in the coronary heart disease.

Methods: We determined the genotyping of TNF-a G-308 A polymorphism by allele-specific polymerase chain reaction assay in 109 cases with coronary heart disease and 120 controls. Allele and genotype frequencies were estimated. The strength of the association of TNF- $a-308 \mathrm{G}>\mathrm{A}$ and risk of coronary heart diseases was measured by odds ratios (ORs) and 95\% confidence interval.

Results: In coronary heart disease and controls, the frequencies of minor allele TNF-a -308 " $\mathrm{A}$ " were 0.190 and 0.158 , respectively, while the frequencies of major allele TNF- $a$ " $G$ " were 0.809 and 0.841 , respectively. The genotype frequencies of TNF- $a-308$ G-A in coronary heart disease cases were $G G=68.81 \%, G A=26.61 \%, A A=4.58 \%$; and the frequencies in controls were $\mathrm{GG}=76.67 \%, \mathrm{GA}=20.83 \%, \mathrm{AA}=2.50 \%$. The $\mathrm{OR}$ for wild related to the TNF-a polymorphism was 0.6714 (0.3737-1.206; $p=0.233)$. The OR for heterozygous was $1.387(0.7468-2.541 p=0.350)$, and the OR for homozygous was $1.857(0.4372-8.041 \mathrm{p}=0.482)$. The differences in AA genotype frequencies of TNF- $\mathrm{a}-308 \mathrm{G}-\mathrm{A}$ between cases and controls have led to an OR $1.857 ; 0.4372-8.041 ; p=0.4829$ in the univariate analysis that was not significant.

Conclusion: No association was observed between the permissive promoter variants in the TNF-a gene and an increased risk of coronary heart disease.

Keywords: Adenosine deaminase, coronary heart disease, high sensitive C-reactive protein, lipid profile, Tumor necrosis factor-alpha -308 G>A polymorphism
\end{abstract}

Coror oronary heart disease (CHD) is defined as acute or chronic cardiac disability caused by imbalance between the myocardial supply and demand for oxygenated blood [1]. Cardiovascular disorders (CVD) are the leading cause of morbidity and mortality. CVD will be the most important cause of mortality in India, and CHD will be the single most vital source to this increasing burden of CVD [2].
According to World Health Organization (WHO), CHD is a modern epidemic, not an unavoidable attribute of aging [3]. The burden of CHD is rising in India. In 2008, CHD caused 7.2 million deaths (i.e., $12.8 \%$ of total deaths) [4].

In the etiology, CHD is caused by any disease affecting the coronary arteries. More than $90 \%$ cases were caused by coronary atherosclerosis and $10 \%$ by other causes like vasospasm,

Address for correspondence: Sangita Mahadev Patil, MD. Department of Biochemistry, Dr. Vithalrao Vikhe Patil Foundations Medical College Ahmednagar, Maharashtra, India

Phone: 9765653919 E-mail: vsrk_om@rediffmail.com

Submitted Date: April 26, 2018 Accepted Date: July 25, 2018 Available Online Date: September 24, 2018

${ }^{\circ}$ Copyright 2018 by International Journal of Medical Biochemistry - Available online at www.internationalbiochemistry.com 
stenosis of coronary ostia, arteritis, embolism, thrombic diseases like shock, polycythemia, and trauma[5].

Inflammation is one of the trademarks of atherosclerosis where the existence of modified low-density lipoprotein particles induces a number of specialized cytokines [6]. Tumor necrosis factor-alpha (TNF-a) is an effective immunomediator and proinflammatory cytokine resultant from endothelial and smooth muscle cells or macrophages associated with atheroma. The occurrence of TNF- $a$ in the atherosclerotic lesion in higher concentration and its absence in normal tissues recommend its involvement in atherogenesis [7].

TNF- $a$ interferes in the metabolic pathways of triglycerides (TG) and cholesterol. It increases plasma TG level by enhancing the concentration of free fatty acids, the substrate of TG synthesis. TNF- $\alpha$ also reduces the clearance of TG-rich lipoproteins. TNF-a might increase hepatic cholesterol synthesis by stimulating the $\beta$-hydroxy $\beta$-methylglutaryl CoA (HMG-CoA) reductase activity in human adipose tissues [6]. TNF- $\alpha$ is a resilient paracrine activator of monocytes and macrophages. It stimulates secretion of products like interleukin- 6 that arouses liver to produce the acute phase reactant $\mathrm{C}$-reactive protein (CRP). In atherosclerotic lesions, TNF- $a$ and CRP are present in significant quantities [8]. Membrane adenosine deaminase regulates cytokine formation on human lymphocytes [9].

$\mathrm{CHD}$ is a multifactorial disease influenced by environmental factors and genetic predisposition. Recently it has been observed that polymorphism directly affected TNF-a expression at gene of nucleotide position 308 [10, 11]. A number of researchers have reported the association of G -308 A polymorphism of the TNF-a gene with myocardial infarction (MI) $[12,13]$. G -308 A polymorphism directly alters the lipid metabolism and endothelial function in CVD. Elahi et al [10] have demonstrated that the $308 \mathrm{~A}$ genotype is related to more severe and rapid progression of coronary atherosclerosis. Juliano C Padovani et al [11] have examined the genetic polymorphisms in the TNF locus (TNF-a $308 \mathrm{G} \rightarrow \mathrm{A}$ ) as risk factors for coronary atherothrombotic disease. In their study, no significant effects were noticed, but they mentioned that polymorphisms in the TNF locus can contribute to atherothrombosis [11].

Many researchers have tested the polymorphisms in TNF- $a$ for genetic association with CHD, but results are controversial $[10,11]$. Therefore, in this study, we investigated the impact of TNF-a-308 G >A polymorphism on serum lipid, plasma hs-CRP, and Adenosine deaminase (ADA) levels in patients with CHD and controls.

\section{Materials and Methods}

This study was conducted at Department of Biochemistry PDVVPF's Medical College Ahmednagar and Swasthya Hospital and Research Centre Ahmednagar (Maharashtra) in alliance with Department of Biochemistry, B. J. Medical College and Sassoon General Hospital (S.G.H) Pune. The study was approved by the ethics committee of B.J.M.C. and S.G.H. Pune. According to the Declaration of Helsinki 1975, informed consent was taken from all participants, and utmost care was taken during experimental procedure.

\section{Study Design:}

Type: Analytical case control study.

Population: Total 229 subjects were enrolled in this study.

Sampling: Simple random sampling

In this study, population was not universal. The study was carried on available individuals that were accessible population. Then, it was divided into groups according to type of CHD, and random samples of varying size were drawn for each group.

\section{Sample size calculation:}

This study was quantitative; thus, the sample size was calculated by using the following formula:

\section{Sample size $n=4 \times \sigma 2 / E 2$}

$\mathrm{n}=$ sample size, $\mathrm{\sigma}=$ standard deviation in population, $\mathrm{E}=$ allowable error

Control group: A total of 120 healthy age and sex matched individuals without any evidence of CHD were involved as control subjects.

Patient group: A total of 109 patients with CHD were included in this study, aged between 26 and 75 years. Of these, patients of $\mathrm{Ml}$ and unstable angina (UA) having chest pain were taken from Intensive Cardiac Care Unit (ICCU). Patients of stable angina were taken from outpatients attending the cardiology department of same hospital who were diagnosed by physicians, blinded to the results of markers; the data included history, physical examination, serial 12-lead electrocardiogram, and cardiac markers' measurement.

Inclusion criteria: The diagnosis of all patients of CHD was made by physicians. Patients who had typical symptoms of CHD like chest pain, sweating, breathlessness, and specific abnormalities for CHD on electrocardiogram and elevated cardiac markers were included in this study.

Exclusion criteria: All patients having diseases of heart valves and myocardium, congenital heart disease, and confounding factors (hypertension, hepatic disease, inflammatory disease, history of recent infection, febrile disorders, diabetes mellitus, and renal insufficiency) that could interfere in the biochemical analysis of study subjects and alter the results were excluded.

\section{Study Protocol:}

After taking informed consents, all subjects were screened for inclusion and exclusion criteria. All the subjects were categorized into two groups: $\mathrm{CHD}$ and controls.

Collection of specimen: Criteria for blood collection were different for different groups.

For control and stable angina, $5 \mathrm{ml}$ blood was collected between 9.00 to $11.00 \mathrm{am}$ after fasting from $10.00 \mathrm{pm}$ of previous day by using $20 \mathrm{G}$ disposable needle from cubital vein with 
aseptic precaution. For UA and MI, $5 \mathrm{ml}$ blood was collected within 12 hours after admission in the ICCU. Plain vacutainer (Yucca Diagnostic) was used for estimation of lipid profile and ADA. Ethylenediaminetetraacetic acid (EDTA) vacutainer (Yucca Diagnostic) was used for assessment of hs-CRP and deoxyribonucleic nucleic acid (DNA) isolation (Hi- Media chemicals, Bio-RAD, Sigma- Aldrich).

After an hour, the samples were centrifuged at $3000 \mathrm{rpm}$ for 10 min to separate serum and plasma. The separated serum and plasma were collected in polythene tube with cork (precautions were taken to avoid the hemolysis), and they were used for analysis of respective parameters. Whole blood was used for DNA extraction (genotyping of TNF-a -308 G-A polymorphism).

\section{Method:}

\section{Estimation of lipid profile:}

Cholesterol oxidase peroxidase (CHOD-PAP) method was used to estimate serum total cholesterol and HDL-C. Enzymatic glycerol 3-phosphate oxidase (GPO-PAP) method for serum TG (kit manufactured by Span Diagnostic Ltd) using semi-autoanalyzer. LDL-C calculated using the Friedewald formula (LDL-C= total cholesterol-TG/5- HDL-C) [14-17].

\section{Determination of hs-CRP by Latex turbidimetric method:} The hs-CRP ultrasensitive turbidimetric test was used to measure low level of C-reactive protein (hs-CRP) in human serum or plasma. Latex particles coated with specific anti-human hsCRP are agglutinated when mixed with sample containing hsCRP. Absorbance changed by agglutination depends upon the content of hs-CRP in the sample that can be quantified by comparison from a calibrator of known hs-CRP concentration [18].

\section{Determination of serum ADA activity:}

The ADA levels were spectrophotometrically measured by the Gusti and Galanti method based on the Berthelot reaction, that is, the formation of colored indophenol complexes from ammonia liberated from adenosine. Intensity of the blue colored indophenol complex formed is directly proportional to the amount of ADA present in the serum sample [19].

\section{Extraction of genomic DNA from whole blood method: salting out [20].}

5. Genotyping of TNF- $a-308$ G-A polymorphism by allelespecific polymerase chain reaction (ASPCR) assay [21, 22]. Genotyping analysis was performed using the polymerase chain reaction (PCR) carried out using Quanta Biotech thermal cycler. The primer pairs F1 (5' TCTCGGTTTCTTCTCCATCG) and R1 (5' ATAGGTTTTGAGGGGCATGG) and F1-R2 (ATAGGTTTTGAGGGGCATGA) were used to amplify a 184-bp fragment of the TNF gene that includes the polymorphic site at the nucleotide position -308 .

Each sample was tested with both primers pairs (F1-R1) and (F1-R2) primer pair F1-R3 (5' GAGTCTCCGGGTCAGAATGA) was

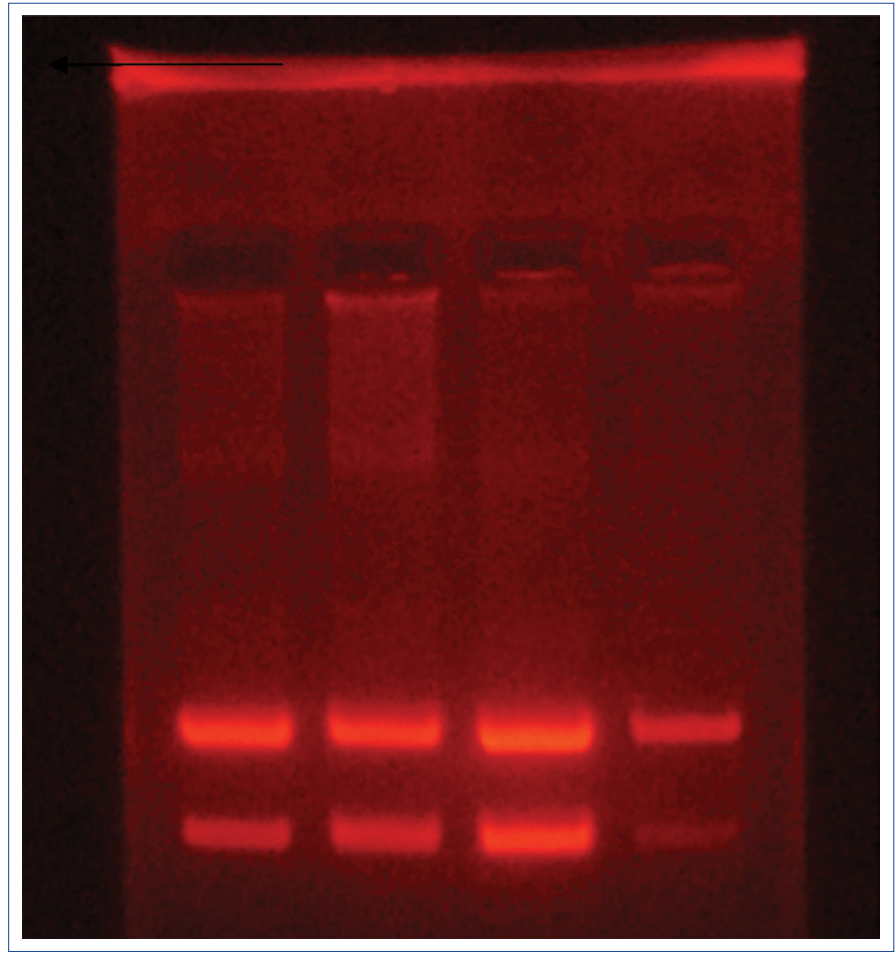

Figure 1. Showing agarose gel electrophoresis of PCR product with primers F1, R1 and R3 indicating presence of wild type of allele for TNF-a -308

used to amplify a TNF gene's fragment of $531 \mathrm{bp}$ as an internal control in the ASPCR and genomic DNA template for sequencing. Primer R3 was also used as competitor for the primer pair F1-R1 and F1-R2 to the specificity of the ASPCR assay.

The PCR reaction was carried out in a total volume of $20 \mu \mathrm{l}$, containing $100 \mathrm{ng}$ of DNA, $0.5 \mathrm{mM}$ of each primer, $0.2 \mathrm{mM}$ of each deoxyribonucleotide, $1 \times$ reaction buffer, $1.5 \mathrm{mM} \mathrm{MgCl}{ }_{2^{\prime}}$ and 1 unit of taq DNA polymerase.

The thermal cycle profile was: initial denaturation at $95^{\circ} \mathrm{C}$ for 10 min followed by 35 cycles denaturation at $94^{\circ} \mathrm{C}$ for $30 \mathrm{~s}$, annealing at $62^{\circ} \mathrm{C}$ for $30 \mathrm{~s}$, and extension at $72^{\circ} \mathrm{C}$ for $60 \mathrm{~s}$. The final extension step was at $72^{\circ} \mathrm{C}$ for $5 \mathrm{~min}$. After amplification, the PCR products were separated by electrophoresis on an agarose gel. Refer Figure 1.

\section{Statistical analysis}

Statistical software SYSTAT version-12 (Cranes Software, Bangalore) was used to analyze the data. The results were expressed in mean \pm standard deviation (mean $\pm S D$ ). Data were analyzed by descriptive statistics as mean, SD, percentage, and so on. Comparisons of study groups and study groups to control groups were done by applying $Z$ test of difference between two sample means at $5 \%(p=0.05)$ and $1 \%(p=0.01)$ level of significance.

The experimental data on the gene polymorphism were converted into categorical variables, and they were compared using the Chi-square test to distinguish the significance of the variation among the subjects. Allele and genotype frequen- 
cies were estimated using SNP stat software. Any deviation of the genotype frequencies from the Hardy-Weinberg equilibrium (HWE) was assessed by Fischer's exact test. The strength of the association between the single nucleotide polymorphisms (SNPs) TNF- $a-308$ G-A and risk of CHD was measured by ORs and $95 \%$ confidence interval. One-way analysis of variance (ANOVA) test was used to find out any significant difference between the means of different variables in different genotypes groups in CHD cases and controls.

\section{Results}

The allele and genotype frequencies of TNF-a -308 G-A related variants have been shown in Table 1. No deviation of the genotype frequencies from the HWE was observed. In CHD and controls, the frequencies of minor allele TNF-a-308 " $A$ " were 0.190 and 0.158 , respectively, while the frequencies of major allele TNF-a-308 "G" were 0.809 and 0.841, respectively.

The genotype frequencies of TNF-a $-308 \mathrm{G}-\mathrm{A}$ in $\mathrm{CHD}$ cases were $\mathrm{GG}=68.81 \%, \mathrm{GA}=26.61 \%, \mathrm{AA}=4.58 \%$, and the frequencies in controls were $\mathrm{GG}=76.67 \%, \mathrm{GA}=20.83 \%, \mathrm{AA}=2.50 \%$. These data yield an overall odds ratio (OR) for association of CHD and controls as shown in Table 2. The OR for wild related to the TNF-a polymorphism was 0.6714 (0.3737-1.206). The OR for heterozygous was $1.387(0.7468-2.541)$, and the OR for homozygous was 1.857 (0.4372-8.041).

Tables 3 and 4 demonstrate the subject characteristics in relation to the TNF- $a-308 \mathrm{G}-\mathrm{A}$ polymorphism in patients with $\mathrm{CHD}$ and controls. There was no significant association between the TNF-a -308 G>A polymorphism and sex, age, body mass index (BMI), and blood pressure in patients with $\mathrm{CHD}$ and controls. By applying one-way ANOVA test and Tukey-Kramer multiple comparison test, the mean values of lipid variables namely TG,

Table 1. Distribution of allele and carrier frequencies of TNF-a -308 G-A for patients with coronary heart disease (CHD) and controls

\begin{tabular}{lcc}
\hline & $\begin{array}{c}\text { CHD Cases }(\mathbf{n}=109) \\
\text { Frequency }\end{array}$ & $\begin{array}{c}\text { Controls }(\mathbf{n}=120) \\
\text { Frequency }\end{array}$ \\
\hline G allele & 0.809 & 0.841 \\
A allele & 0.190 & 0.158 \\
Carrier & $30.87 \%$ & $26.62 \%$
\end{tabular}

Table 2. Estimated genotype frequencies and odds ratios for association with coronary heart disease (CHD) and controls

\begin{tabular}{lcccc}
\hline Genotype & $\begin{array}{c}\text { CHD } \\
\text { patients }\end{array}$ & Controls & OR ratio & $\begin{array}{c}\text { 'p'value and } \\
\text { significance }\end{array}$ \\
\hline GG & 75 & 92 & $\begin{array}{c}0.6714 \\
(0.3737-1.206)\end{array}$ & 0.2335 \\
& & 25 & $\begin{array}{c}1.387 \\
(0.7468-2.541)\end{array}$ & 0.3507 \\
GA & 29 & 2 & $\begin{array}{c}1.857 \\
(0.4372-8.041)\end{array}$ & 0.4829 \\
AA & 5 & 3 & &
\end{tabular}

total cholesterol, LDL-C, and HDL-C as well as the hs-CRP and ADA in wild (GG) genotype and mutant genotype (GA heterozygote and AA homozygote) groups of CHD and controls were not significantly altered. $p<0.05$ is considered as significant.

\section{Discussion}

Cardiovascular diseases, generally coronary artery disease, cause sudden death, which is also called a natural death. It occurs due to cardiac causes through abrupt loss of consciousness within one hour of the onset of acute symptoms [1]. Pathological process that happens in CHD may be triggered and enhanced by inflammation and environmental and genetic risk factors, and they are mediators of pathogenesis of these diseases [6].

TNF-a is a protein that contains 233 amino acids coded by the small 4 exon TNF-a gene. (1585 base pair) located at chromosome 6 (p21) [23]. It is an effective immunomediator and proinflammatory cytokine that is concerned with pathogenesis of several diseases including rheumatoid arthritis, trauma, and sepsis. It plays an important role in the development of atherosclerosis lesions. It stimulates the expression of adhesion molecules on endothelial cells and inflammatory cells activation as well as increasing initiation process of the inflammatory cascade inside the arterial wall [6].

Recently, it has been identified that polymorphism at nucleotide position -308 of the promoter region of gene directly affects the TNF-a expression. These genetic variations result in two possible allele forms in which the presence of guanine describes the common variant $(G)$, whereas adenine terms the less common allele (A) [24]. The presence of A allele is significantly connected with more TNF-a-producing autoimmune major histocompatibility complex III (MHC) haplotype HLA-A1, B8, and DR3 with raised serum TNF-a levels.

In this study, we examined the relationship between the TNF-a-308 G-A polymorphism and risk of CHD. The allele and genotype frequencies of TNF- $a-308 \mathrm{G}-\mathrm{A}$ related variants have been enumerated in Table 1. No deviation of the genotype frequencies from the HWE was observed. In CHD and controls, the frequencies of minor allele TNF-a-308 " $\mathrm{A}$ " were 0.190 and 0.158 , respectively, while the frequencies of major allele TNF-a-308 "G" were 0.809 and 0.841 , respectively. There is a wide variation in the incidence of the A allele in different populations across the world. The maximum frequency $(0.274)$ was recorded in a Caucasian population. Data from the HapMap pointed out the frequency of the A allele in Europeans to be 0.27 , whereas in the Japanese population it was 0.02 [25]. Recently in case-control study, Aparana et al have found the A allele frequencies were 0.06 and 0.02 in coronary artery disease (CAD) and controls correspondingly in population of Western India [26].

The genotype frequencies of TNF-308 G-A in CHD cases were $\mathrm{GG}=68.81 \%, \mathrm{GA}=26.61 \%, \mathrm{AA}=4.58 \%$, and the frequencies 
in controls were $\mathrm{GG}=76.67 \%, \mathrm{GA}=20.83 \%, \mathrm{AA}=2.50 \%$. These data yield an overall OR for association of CHD and controls as shown in Table 2 . The OR for wild related to the TNF-a polymorphism was 0.6714 (0.3737-1.206). The OR for heterozygous was 1.387 (0.7468-2.541), and the OR for homozygous was $1.857(0.4372-8.041)$.

Thus in this study, the differences in AA genotype frequencies of TNF-308 G-A between cases and controls have led to an OR $1.857 ; 0.4372-8.041 ; p=0.4829$ in the univariate analysis that was not significant. This means that no association was observed between the permissive promoter variants in the TNF-a gene and an increased risk of CAD. Our results collaborate with the finding of Juliano et al. [11] According to them, genotype frequencies of GG, GA, and AA were $81 \%, 26 \%$, and $2 \%$, respectively, in patients with $\mathrm{Ml}$, while $76.7 \%, 22.3 \%$, and $0.6 \%$ in controls. Their finding recommended that relationship of polymorphism in the TNF locus with major risk factors for
CHD might not exist [11]. Bhanushali et al. [26] have observed that there is no any association between the TNF-a gene and increased risk of CAD. In meta-analysis and case-control study, Chu et al. [13] have shown that no association exists between the TNF-a -308 G-A (rs1800629) polymorphism of the TNF-a gene (presence of A allele) and CHD/MI in the Chinese Han population. They also demonstrated that there was no evidence of difference in the risk effects of rs1800629 between Caucasians and Asians.

Koch et al. [27] have assessed the interleukin -10 and TNF polymorphism in CAD and MI. They advised that six different and functionally relevant polymorphism of the gene for interleukin- $a(-1082 \mathrm{G} / \mathrm{A},-819 \mathrm{C} / \mathrm{T}$ and 592C/A), TNF-a (-863C/A,$308 \mathrm{G} / \mathrm{A})$, and TNF- $\beta(252 \mathrm{G} / \mathrm{A})$ are not associated with the risk of CAD or MI in angiographically examined patients.

Ghazouani et al. [28] have performed the TNF-a -308 G>A and IL-6-174 G >C polymorphism in Tunisian patients with CAD.

Table 3. Subject characteristics in relation to the TNF- $a-308 G-A$ polymorphism in CHD

\begin{tabular}{|c|c|c|c|c|}
\hline Variables & GG & GA & AA & P-value \\
\hline Male & 44 & 22 & 3 & 0.3466 \\
\hline Systolic blood pressure $(\mathrm{mm} \mathrm{Hg})$ & $136.80 \pm 27.37$ & $139.66 \pm 26.25$ & $136.0 \pm 29.66$ & 0.8838 \\
\hline Diastolic blood pressure (mm Hg) & $85.20 \pm 19.55$ & $90.0 \pm 18.90$ & $92.80 \pm 25.08$ & 0.4223 \\
\hline HDL-Cholesterol (mg/dl) & $35.15 \pm 4.34$ & $36.71 \pm 5.12$ & $35.02 \pm 2.66$ & 0.2802 \\
\hline LDL-Cholesterol (mg/dl) & $210.55 \pm 59.08$ & $202.36 \pm 64.49$ & $185.33 \pm 61.40$ & 0.5892 \\
\hline Triglyceride (mg/dl) & $186.49 \pm 53.45$ & $178.81 \pm 53.28$ & $183.34 \pm 21.50$ & 0.7998 \\
\hline $\mathrm{hs}-\mathrm{CRP}(\mathrm{mg} / \mathrm{l})$ & $4.06 \pm 2.03$ & $3.90 \pm 2.41$ & $3.20 \pm 1.95$ & 0.6696 \\
\hline Adenosine deaminase (U/L) & $54.55 \pm 22.24$ & $54.00 \pm 19.86$ & $59.75 \pm 16.58$ & 0.51 \\
\hline
\end{tabular}

By applying one-way ANOVA test and Tukey-Kramer multiple comparison test, biochemical parameters such as total cholesterol, HDL-C, LDL-C, TG, hs-CRP, and ADA are not significantly altered in all genotypes like GG, GA, and AA in patient with CHD. $p<0.05$ is considered as statistically significant.

Table 4. Subject characteristics in relation to the TNF-a -308G-A polymorphism in control

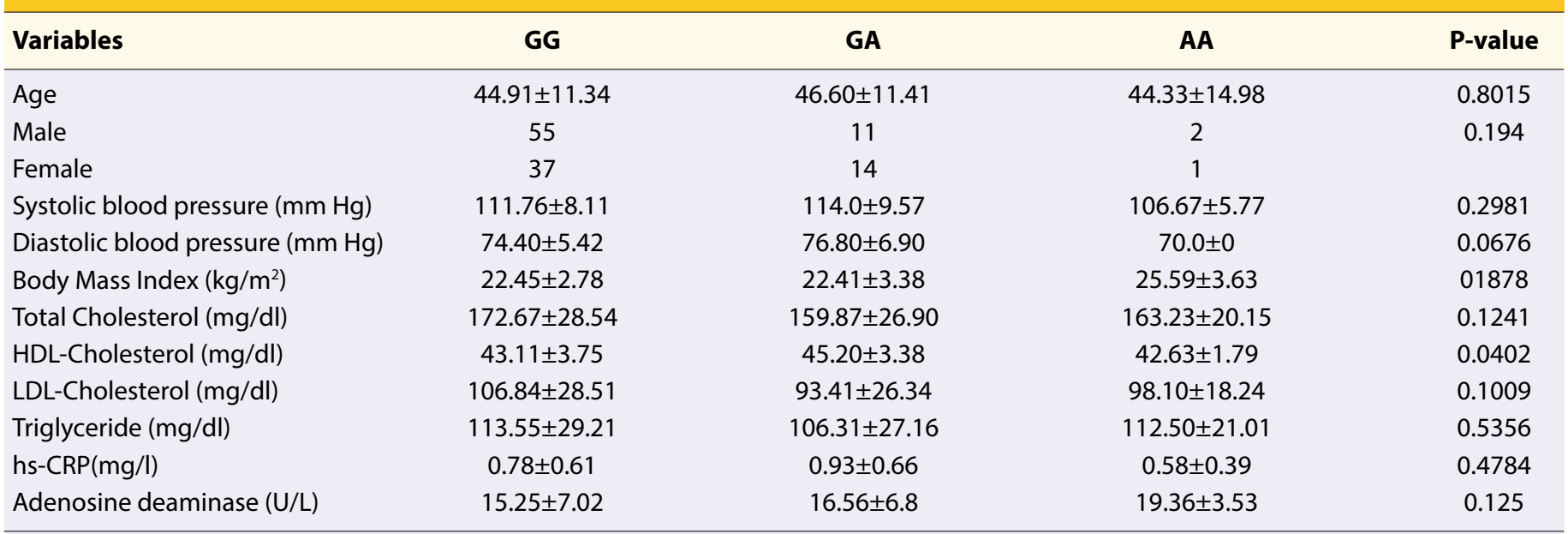

$p<0.05$ is considered as statistically significant. 
According to their study, significant differences were not observed in allele distribution of TNF-a-308 A (19.6\% vs $19.0 \%$; $\mathrm{p}=0.73$ ) promoter polymorphism between $C A D$ and control subjects.

Controversially, Chang et al. [29] and El Naggar et al. [30] suggested that TNF-a-308 A>G is associated with increased risk of $C A D$ and $M I$ with other metabolic diseases like obesity and type 2 diabetes mellitus. They explained that the $G$ to $A$ substitute of -308 nucleotide located in the promoter region of the TNF-a gene alters its mRNA transcription level and contributes to raise TNF-a secretion in serum. Higher concentration of proinflammatory cytokines might quicken the formation of plaque rupture through the initiation of unusual apoptosis activities of the cardiomyocytes and simultaneously modulate the acute Ml onset risk.

In this study (Tables 3,4), no significant relationship was observed between the TNF- $a-308 \mathrm{G}>\mathrm{A}$ polymorphism and sex, age, BMl, and blood pressure in patients with $\mathrm{CHD}$ and controls. This is in agreement with a number of studies including with outcome of Chu et al. [13] who demonstrated that A allele was not associated with increased risk of CHD after adjusting for sex, age, BMI, diabetic mellitus, and smoking status.

TNF-a interferes with the metabolic pathways of TG and cholesterol. It increases plasma TG level by enhancing the concentration of free fatty acids, the substrate of TG synthesis. TNF- $a$ also reduces the clearance of TG-rich lipoproteins. TNF-a might increase hepatic cholesterol synthesis by stimulating the $\beta$-hydroxy $\beta$-methylglutaryl CoA (HMG-CoA) reductase activity in human adipose tissues [6]. TNF- $a$ is a resilient paracrine activator of monocytes and macrophages. It stimulates secretion of products like interleukin- 6 that arouses liver to produce the acute phase reactant CRP. In atherosclerotic lesions, TNF- $\alpha$ and CRP are present in significant quantities [8]. Membrane adenosine deaminase regulates cytokine formation on human lymphocytes [9].

Therefore, in this study, we investigated the impact of TNF-a $-308 \mathrm{G}>\mathrm{A}$ polymorphism on serum lipid, plasma hs-CRP, and ADA levels in patients with CHD and controls.

Thus by applying one-way ANOVA test and Tukey-Kramer multiple comparison test, the mean values of lipid variables namely TG, total cholesterol, LDL-C, and HDL-c as well as the hs-CRP and ADA in wild (GG) genotype and mutant genotype (GA heterozygote and AA homozygote) groups of CHD and controls were not significantly altered (Tables 3,4 ) Our results strongly support the earlier work done by Bhanushali et al. that confirmed that there is no association of the TNF- $a-308$ genotypes with any of the lipid parameters [26]. Gander et al. [8] have tried to find the relation of polymorphism and its effect on plasma CRP level. According to them, TNF- $-\mathrm{-}-308 \mathrm{G}>\mathrm{A}$ polymorphism did not significantly affect plasma levels of CRP [8].

In contrast to our study, Parra-Rojas et al. [31] have found the significant alternation of lipid parameters in Mexican population. They stipulated that high levels of TG and total cholesterol along with low HDL-C levels were associated with GG genotype of -308 TNF-a polymorphism. This dissimilarity may be due to inherent complexities in studying the interaction between inflammation and lipid metabolism in vivo due to anorexia produced by the proinflammatory cytokines [31]. Thus, no association was observed between the permissive promoter variants in the TNF-a gene and an increased risk of CHD. TNF-a $-308 \mathrm{G}>\mathrm{A}$ polymorphism may not directly affect the serum level of lipid variables, plasma level of hs-CRP and ADA.

\section{Conclusion}

As TNF-a is an important contributor to the development of atherosclerosis lesions, no association was observed between the permissive promoter variants in the TNF- $a$ gene and an increased risk of CHD. TNF- $a-308 \mathrm{G}>\mathrm{A}$ polymorphism may not directly affect the serum level of lipid variables, plasma ADA, and hs-CRP. Therefore, there is no evidence of a difference in risk effects of TNF- $a-308 \mathrm{G}>\mathrm{A}$ polymorphism between CHD and controls.

Acknowledgment: The author acknowledges the doctors and technical staff in ICCU of Vikhe Patil Hospital \& Swasthya Hospital \& Research Centre Ahmednagar for their cooperation in collection of blood within time.

Ethics Committee Approval: The study was approved by the ethics committee of B.J.M.C. and S.G.H. Pune.

Conflict of interest: No any conflict of interest.

Peer-review: Externally peer-reviewed.

\section{References}

1. Mohan H, Dagajamov I. Textbook of pathology forward Ivan Danjanov. 5th ed. New Delhi: Jaypee Brothers; 2005. p. 305-26.

2. Gupta N, Gill KD, Singh S. Paraoxonase 1 (PON1) Activity, Polymorphisms and Coronary Artery Disease. Available at: https:// www.intechopen.com/books/coronary-artery-disease-newinsights-and-novel-approaches/paraoxonase-1-pon1-activity-polymorphisms-and-coronary-artery-disease. Accessed Aug 6, 2018.

3. Reddy KK, Rao AP, Reddy TP. Socioeconomic status and the prevalence of coronary heart disease risk factors. Asia Pacific J Clin Nutr 2002;11:98-103. [CrossRef]

4. World Health Organization. Disease, injury and causes of death regional estimates, 2004-2008-cause-specific mortalıty: regional estimates for 2008. WHO; 2011. Available at: http:// www.who.int/healthinfo/global_burden_disease/estimates_ regional_2004_2008/en/.Accessed Aug 6, 2018.

5. Park K. Park's Textbook of Preventive and Social Medicine. 18th ed. Jabalpur; M/s Banarsidas Bhanot Publishers; 2005. p. 28690.

6. Popa C, Netea MG, van Riel PL, van der Meer JW, Stalenhoef AF. The role of TNF-alpha in chronic inflammatory conditions, intermediary metabolism, and cardiovascular risk. J Lipid Res 2007;48:751-62. [CrossRef] 
7. Ridker PM, Rifai N, Pfeffer M, Sacks F, Lepage S, Braunwald E. Elevation of tumor necrosis factor-alpha and increased risk of recurrent coronary events after myocardial infarction. Circulation 2000;101:2149-53. [CrossRef]

8. Gander ML, Fischer JE, Maly FE, von Känel R. Effect of the G308A polymorphism of the tumor necrosis factor (TNF)-alpha gene promoter site on plasma levels of TNF-alpha and C-reactive protein in smokers: a cross-sectional study. BMC Cardiovasc Disord 2004;4:17. [CrossRef]

9. Pacheco R, Martinez-Navio JM, Lejeune M, Climent N, Oliva H, Gatell JM, et al. CD26, adenosine deaminase, and adenosine receptors mediate costimulatory signals in the immunological synapse. Proc Natl Acad Sci U S A 2005;102:9583-8. [CrossRef]

10. Elahi MM, Gilmour A, Matata BM, Mastana SS. A variant of position -308 of the Tumour necrosis factor alpha gene promoter and the risk of coronary heart disease. Heart Lung Circ 2008;17:14-8. [CrossRef]

11. Padovani JC, Pazin-Filho A, Simões MV, Marin-Neto JA, Zago MA, Franco RF. Gene polymorphisms in the TNF locus and the risk of myocardial infarction. Thromb Res 2000;100:263-9.

12. Wang XL, Oosterhof J. Tumour necrosis factor alpha G-308->A polymorphism and risk for coronary artery disease. Clin Sci (Lond) 2000;98:435-7. [CrossRef]

13. Chu H, Yang J, Mi S, Bhuyan SS, Li J, Zhong L, et al. Tumor necrosis factor-alpha G-308 A polymorphism and risk of coronary heart disease and myocardial infarction: A case-control study and meta-analysis. J Cardiovasc Dis Res 2012;3:84-90.

14. Herbart K. Lipids. In: Kaplan LA, Pesce AJ, editors. Clinical Chemistry: Theory, analysis and co-relation. Toronto: CV Mosby; 1984. p. 1182-230.

15. Nader R, Paul B, John A Lipids, Lipoproteins and apolipoproteins. In: Burtis CA, Ashwood ER, editors. Tietz Textbook of Clinical Chemistry. 3rd ed. Philadelphia: W.B. Saunders; 1994. p. 809-52.

16. Kaplan A, Lavernel LS. Lipid metabolism. In: Clinical chemistry: Interpretation and techniques. 2nd ed. Philadelphia: Lea Febiger; 1983. p. 333-6.

17. McGowan MW, Artiss JD, Strandbergh DR, Zak B. A peroxidase-coupled method for the colorimetric determination of serum triglycerides. Clin Chem 1983;29:538-42.

18. Ridker PM, Hennekens $\mathrm{CH}$, Buring JE, Rifai N. C-reactive protein and other markers of inflammation in the prediction of cardiovascular disease in women. N Engl J Med 2000;342:836-43.

19. Giusti G, Galanti B. Colorimetric method. In: Bergmeyer HU, editor. Methods of Enzymatic Analysis. 3rd ed. Weinheim; Verlag Chemie; 1984. p. 315-23.

20. Kalousová M, Levová K, Kuběna AA, Jáchymová M, Franková V,
Zima T. Comparison of DNA isolation using salting-out procedure and automated isolation (MagNA system). Prep Biochem Biotechnol 2017;47:703-8. [CrossRef]

21. Zhu KY, Clark JM. Addition of a competitive primer can dramatically improve the specificity of PCR amplification of specific alleles. Biotechniques 1996;21:586. [CrossRef]

22. Warzocha K, Ribeiro P, Bienvenu J, Roy P, Charlot C, Rigal D, et al. Genetic polymorphisms in the tumor necrosis factor locus influence non-Hodgkin's lymphoma outcome Blood 1998;91:3574-81.

23. Mizia-Stec K, Gasior Z, Zahorska-Markiewicz B, Janowska J, Szulc A, Jastrzebska-Maj E, et al. Serum tumour necrosis factor-alpha, interleukin-2 and interleukin-10 activation in stable angina and acute coronary syndromes. Coron Artery Dis 2003;14:431-8. [CrossRef]

24. Elahi MM, Asotra K, Matata BM, Mastana SS. Tumor necrosis factor alpha -308 gene locus promoter polymorphism: an analysis of association with health and disease. Biochim Biophys Acta 2009;1792:163-72. [CrossRef]

25. Perrey C, Pravica V, Sinnott PJ, Hutchinson IV. Genotyping for polymorphisms in interferon-gamma, interleukin-10, transforming growth factor-beta 1 and tumour necrosis factor-alpha genes: a technical report. Transpl Immunol 1998;6:193-7.

26. Bhanushali AA, Das BR. Promoter variants in interleukin- 6 and tumor necrosis factor alpha and risk of coronary artery disease in a population from Western India. Indian J Hum Genet 2013;19:430-6. [CrossRef]

27. Koch W, Kastrati A, Böttiger C, Mehilli J, von Beckerath N, Schömig A. Interleukin-10 and tumor necrosis factor gene polymorphisms and risk of coronary artery disease and myocardial infarction. Atherosclerosis 2001;159:137-44. [CrossRef]

28. Ghazouani L, Ben Hadj Khalifa S, Abboud N, Ben Hamda K, Ben Khalfallah A, Brahim N, et al. TNF-alpha -308G >A and IL-6 $-174 G>C$ polymorphisms in Tunisian patients with coronary artery disease. Clin Biochem 2010;43:1085-9. [CrossRef]

29. Chang WT, Wang YC, Chen CC, Zhang SK, Liu CH, Chang FH, et al. The $-308 \mathrm{G} / \mathrm{A}$ of Tumor Necrosis Factor (TNF)-a and 825C/T of Guanidine Nucleotide Binding Protein 3 (GNB3) are associated with the onset of acute myocardial infarction and obesity in Taiwan. Int J Mol Sci 2012;13:1846-57. [CrossRef]

30. El Naggar GF, El-Serogy $H$. Is there a relation between TNF-a 308 Promoter Gene Polymorphism and a risk of Coronary Artery Disease In patients with Type 2 Diabetes Mellitus? Life Science Journal 2013;10:1779-85.

31. Parra-Rojas I, Ruíz-Madrigal B, Martínez-López E, Panduro A. Influence of the -308 TNF-alpha and -174 IL-6 polymorphisms on lipid profile in Mexican subjects. Hereditas 2006;143:167-72. 